\title{
Visceral leishmaniasis (kala-azar) and pregnancy
}

\author{
Ernesto Antonio Figueiró-Filho, Geraldo Duarte, Patrícia El-Beitune, \\ Silvana Maria Quintana and Tamara Lemos Maia
}

\author{
Department of Gynecology and Obstetrics, Faculty of Medicine of Ribeirão Preto, University of São Paulo, \\ Ribeirão Preto, Brazil
}

Objective: The aim of the present review was to close the gap in the approach to pregnant women with visceral leishmaniasis (kala-azar) by providing up-to-date information to obstetricians about physiopathology, epidemiology, vertical transmission, drugs and treatment during pregnancy.

Background: Infection with Leishmania chagasi during pregnancy is rare and deserves special attention since little information is available regarding the occurrence of visceral leishmaniasis during gestational period and the real possibility of vertical transmission of this disease. Because specific areas in the world are endemic for the disease and considering the continuous growth of the population, cases of pregnant women with visceral leishmaniasis are becoming more frequent. Unfortunately, textbooks on infectious diseases do not include this specific group of patients, and studies in the literature on aspects related to pregnancy and visceral leishmaniasis are scarce.

Conclusions: Vertical transmission of leishmaniasis is possible and the institution of treatment is imperative in cases of pregnant women with kala-azar. Amphotericin B is strongly recommended as the first choice drug due to its fewer maternal-fetal adverse effects.

Key words: Review; Tropical Infection; AMPHOtericin B; Vertical Transmission, CONGENital INFECTION

\section{INTRODUCTION}

According to Alencar et al. ${ }^{1}$ visceral leishmaniasis (VL) or kala-azar was first described in Greece in 1835, and subsequently in India in 1882. At that time, emphasis was placed on a typical aspect of the disease found in India, which did not usually manifest itself in Brazil, i.e. the darkening of the skin. This characteristic formed the basis of the first denomination of this disease, which was called 'black fever', 'kala-jwar' or 'kalazar' by Indians. Almost at the same time, in 1903, Laveran and Mesnil identified the parasite in material provided by
Leishman and Donovan. In honor of Leishman, the disease associated with this parasite was called leishmaniasis, which is the most widely used terminology in western countries ${ }^{1}$.

$\mathrm{VL}$ is a zoonosis of worldwide distribution and mainly affects populations in developing countries. In addition to humans, VL is also found in animals and its transmission, initially through wild animals and so usually concentrated in small rural localities, is increasingly observed in medium and large urban centers in domiciliary and peridomiciliary areas. The progressive expansion of VL qualifies this disease as a public health problem in Brazil and in other South American countries due

Correspondence to: Ernesto Antonio Figueiró Filho, Rua das Garças, 427, Centro, CEP: 79010-020, Campo Grande - MS, Brazil. Email: eafigueiro@uol.com.br 
to its endemic and sociodemographic characteristics $^{2-4}$.

$\mathrm{VL}$ is a chronic systemic disease that is characterized by persisting fever, weight loss, asthenia, adynamia and anemia, among other clinical manifestations. The disease is fatal when untreated, with death generally occurring 1 to 2 years after the onset of clinical manifestations. The etiological agent of this zoonosis is the protozoan Leishmania chagasi, genus Leishmania, family Trypanosomatidae. Its evolutive cycle is characterized by two forms: the amastigote form (without flagella), an obligatory intracellular stage in vertebrates; and the promastigote form (flagellated) found in the digestive tube of the insect vector and in artificial culture media ${ }^{1,2,5,6}$.

The reservoirs of $L$. chagasi are to be found in the wild in foxes and marsupials. In urban areas, the main source of infection is dogs, which might develop clinical signs of the disease such as weight loss, piloerection and loss of fur, nodules or ulcerations in the ears, intestinal hemorrhage, paralysis of the hind limbs, keratitis accompanied by blindness, and cachexia, leading to death in more severe cases. Since canids show intense cutaneous parasitism, infection of the mosquito vector is facilitated, and therefore these animals become the most important link in the maintenance of the epidemiological chain ${ }^{1-3}$.

In Brazil, the main vector responsible for the transmission of VL is Lutzomyia longipalpis, a small mosquito of sand-like color (sandfly) with large hairy wings directed backwards and upwards, a flexed head, a gibbous body, and long maxillary palpi. The mosquito inhabits the domiciliary and peridomiciliary areas of human dwellings where it feeds on the blood of dogs, humans, birds and other mammals. Females have anthropophilic habits, since they require blood for the development of their eggs ${ }^{1,2}$.

The mosquito becomes infected during a blood meal through the ingestion of the amastigote forms of Leishmania, found in the cytoplasm of cells of the mononuclear phagocyte system (macrophages) present in the dermis of the infected host. In the midgut of the sandfly, the amastigote forms transform into promastigotes which adhere to the epithelium of the digestive tube, initiating the process of multi- plication (sexual) with migration to the anterior intestine and differentiation into infectious promastigote forms, followed by invasion of the insect's pharynx. The females become infectious 3 to 4 days after feeding on contaminated blood $^{1,2,5,6}$.

During a new blood meal, infectious promastigote forms are deposited together with the saliva of the sandfly inside the dermis of another host, followed by the invasion of macrophages. These infectious forms invade new macrophages where they transform into amastigotes inside parasitophorous vacuoles and multiply until rupture of the vacuole, which is followed by the invasion of new macrophages. Hematogenic dissemination to other tissues rich in cells of the mononuclear phagocyte system, such as lymph nodes, liver, spleen and bone marrow is observed ${ }^{1,2,5,6}$.

The incidence of VL shows a sporadic or endemoepidemic character in 18 (66.7\%) states of Brazil, with most Brazilian cases having been reported in the north-eastern states. About $60 \%$ of cases of the disease have been reported in children younger than 4 years of age $e^{7,8}$. On the other hand, the involvement of adults has significant repercussions on the epidemiology of VL due to the presence of asymptomatic forms, in addition to clinically expressed forms ${ }^{1-3}$.

Special attention should be paid to women infected with $L$. chagasi during pregnancy, since little information is available regarding the proportion of infected pregnant women or their geographical distribution. Kala-azar in pregnancy is considered to be a rare occurrence in view of the cases reported in the literature. However, with the disease spreading among urban and peri-urban areas in Brazil, where adults were generally not previously exposed to Leishmania, cases of pregnant women with VL have been reported $^{9}$. Unfortunately, textbooks on infectious diseases do not include this specific group of patients, and studies in the literature on aspects related to pregnancy and visceral leishmaniasis are scarce ${ }^{1-6,9}$. The aim of this review was to close the gap in the approach to pregnant women with VL by providing up-to-date information to obstetricians about the management of women affected by leishmaniasis during pregnancy. 


\section{VERTICAL TRANSMISSION OF VISCERAL LEISHMANIASIS}

Although the insect vector represents the most frequent and the most important route of transmission of VL, other exceptional routes of transmission have also been described, such as direct dog-to-dog transmission, tick bites, blood transfusion, sexual transmission, organ transplants, and mother-child or congenital transmission which is also called vertical transmission $^{1,4}$.

Transplacental vertical transmission of leishmaniasis has been studied experimentally in pregnant dogs ${ }^{10,11}$, however, Andrade et al. ${ }^{12}$ did not confirm this form of transmission in these animals, suggesting that the experimental vertical transmission reported by others might have occurred during delivery. Despite the consistency of the study by Andrade et al. ${ }^{12}$, the transplacental passage of various parasites such as trypanosomatids and helminths has been well established in different experimental investigations using models of pregnant $\operatorname{animals}^{13-17}$

Until now, human studies detailing and confirming the vertical transmission of VL have not been available. Evidence that the mother-tochild transmission of VL is possible, although rare, is known because of the human cases of congenital VL that have been described worldwide since 1926, emphasizing the strong possibility of the vertical transmission of Leishmania chagasi ${ }^{4,18-26}$.

Low and Cooke $^{18}$ reported the first case of kala-azar in pregnancy, which occurred in Africa, with the child showing signs and symptoms of the disease at birth. Banerji ${ }^{19}$ reported the case of a child born in England who manifested clinical signs and symptoms of laboratory confirmed VL at 7 months of age. The child's mother, whose disease was acquired at 5 months gestation, was returning to England from India where she had lived for several years.

Nyakundi et al. ${ }^{22}$ also reported on a 4-monthold male infant born prematurely after 6 months gestation with kala-azar. The child's mother was diagnosed as having VL during pregnancy. The authors assumed that chronic infection with kala- azar in the mother may have been the cause of the reported previous fetal wastage.

Yadav et al. ${ }^{23}$ described an 11-month-old male infant admitted with symptoms that were later confirmed as VL. The baby's mother had also suffered from kala-azar while carrying this child. As the baby and his mother did not leave New Delhi, India, where the case was related, either during or after the delivery and the vector found in New Delhi was not competent to transmit leishmaniasis, the infant could not have been infected by the bite of a sandfly. It therefore seems most likely that he was congenitally exposed to kala-azar.

Eltoum et al. ${ }^{24}$ reported two cases of congenital kala-azar in the Sudan. The first child, whose mother had contracted kala-azar in southern Sudan, was born in a Sudan area where no transmissions of leishmaniasis were currently occurring. At 7 months the child developed characteristic symptoms of VL and died. The autopsy showed leishmania parasites in all tissue, including lungs, kidneys and thymus. In the second case, parasites were found in the placenta of a five-month-old fetus, confirming the Leishmania's transplacental passage during pregnancy.

Meinecke et al. ${ }^{4}$ reported the case of a 16month-old German boy who was admitted to hospital with signs and symptoms later confirmed as VL. Because the child had never left Germany, nonvector transmission was suspected. His mother had travelled to endemic Mediterranean areas (Portugal, Malta and Corsica) several times during her pregnancy. She had never been symptomatic for kala-azar, but she had a positive Montenegro skin test, indicating a previous infection with Leishmania. In this case it was also assumed that the asymptomatic mother must have had a subclinical infection with Leishmania that was reactivated by pregnancy, and had then congenitally transmitted it to the child.

Table 1 data summarizes the cases of VL reported thus far, indicating the real possibility of mother-to-child transmission of this disease. In almost all cases the mothers were symptomatic and no treatment was established during pregnancy, although all the newborns received specific treatment against the infection ${ }^{4,18-26}$. 
Table I Cases of congenital visceral leishmaniasis according to year of publication, country of origin, clinical manifestations, maternal treatment and the treatment and evolution of the newborn

\begin{tabular}{|c|c|c|c|c|c|c|}
\hline \multirow[b]{2}{*}{ Case } & \multirow[b]{2}{*}{ Reference } & \multirow[b]{2}{*}{ Country } & \multicolumn{2}{|c|}{ Mother } & \multicolumn{2}{|c|}{ Newborn } \\
\hline & & & Symptoms & Treatment & Treatment & Evolution \\
\hline I & Low and Cooke ${ }^{18}$ & England & Yes & No & Yes & Cure \\
\hline 2 & Banerji ${ }^{19}$ & India & Yes & No & Yes & Cure \\
\hline 3 & Blanc and Robert ${ }^{20}$ & France & Yes & No & Yes & Cure \\
\hline 4 & Mittal et al. ${ }^{21}$ & India & Yes & No & Yes & Cure \\
\hline 5 & Nyakundi et al. ${ }^{22}$ & Kenya & Yes & No & Yes & Cure \\
\hline 6 & Yadav et al. ${ }^{23}$ & India & Yes & No & Yes & Cure \\
\hline $7-8$ & Eltoum et al. ${ }^{24}$ & Sudan & Yes & No & Yes & Death \\
\hline 9 & Elamin and Omer ${ }^{25}$ & Sudan & Yes & No & Yes & Death \\
\hline 10 & Sharma et al. ${ }^{26}$ & India & No & No & Yes & Cure \\
\hline II & Meinecke et al. ${ }^{4}$ & Germany & No & No & Yes & Cure \\
\hline
\end{tabular}

\section{CLINICAL AND LABORATORY ASPECTS OF VISCERAL LEISHMANIASIS}

The clinical manifestations of VL during pregnancy do not differ from those observed in nonpregnant patients, reflecting an imbalance between multiplication of the parasite in cells of the mononuclear phagocyte system, the patient's immune response, and the underlying inflammatory process. Many infected individuals show the inapparent or oligosymptomatic form of the disease, and the number of severe cases or cases with clear clinical manifestations is relatively small. Causes of death in patients with VL generally include hemorrhage and associated infections due to physical and immunological debilitation. Didactically, VL can be classified into several different forms in order to facilitate its study ${ }^{1-3}$.

(A) Inapparent: patients with positive serology or positive leishmanin test (Montenegro skin test), or the detection of parasites in tissue, without clinical manifestations.

(B) Oligosymptomatic: intermittent picture of low or absent fever. Hepatomegaly is present and splenomegaly, when detected, is discrete. Adynamia and cachexia are observed, but there are no reports of hemorrhage.

(C) Acute: the onset can be abrupt or insidious. In most cases fever is the first symptom, which can be high and continuous or intermittent, followed by remission within 1 or 2 weeks. Hepatosplenomegaly, adynamia, weight loss and hemorrhage are observed in addition to anemia accompanied by hyperglobulinemia.

(D) Classic: a picture of prolonged evolution which leads to nutritional impairment accompanied by hair loss, ciliary growth and brightness, and edema of the lower limbs. Manifestations include fever, asthenia, adynamia, anorexia, weight loss and cachexia. Marked hepatosplenomegaly, generalized micropolyadenopathy, and intense pallor of the skin and mucosae as a consequence of the severe anemia are observed. Hemorrhagic phenomena such as gingival bleeding, epistaxis, ecchymoses and petechiae are frequent. Laboratory exams reveal marked anemia, leukopenia, thrombocytopenia (pancytopenia), hyperglobulinemia, and hypoalbuminemia.

(E) Refractory: this is the evolutive form of classic VL, which does not respond to antimony treatment and is therefore considered to be clinically more severe.

The most common signs and symptoms according to the presentation forms of visceral leishmaniasis are listed on Table 2. 
Table 2 Kala-azar clinical presentations and the most common signs and symptoms

\begin{tabular}{lcccccccc}
\hline & \multicolumn{7}{c}{ Most common signs and symptoms } \\
\cline { 2 - 8 } $\begin{array}{l}\text { Kala-azar clinical } \\
\text { presentation }\end{array}$ & $\begin{array}{c}\text { Hyperglo- } \\
\text { bulinemia }\end{array}$ & Anemia & Fever & $\begin{array}{c}\text { Hepato- } \\
\text { megaly }\end{array}$ & $\begin{array}{c}\text { Spleno- } \\
\text { megaly }\end{array}$ & Adynamia & Weight loss Hemorrhage \\
\hline Oligosymptomatic & - & - & $+/-$ & $+/-$ & $+/-$ & $+/-$ & $+/-$ & - \\
Acute & + & $+/++$ & $+/++$ & $+/++$ & $+/++$ & $+/++$ & $+/++$ & $-/+/++$ \\
Classic & ++ & $++/+++$ & $++/+++$ & +++ & +++ & $++/+++$ & $++/+++$ & $++/+++$ \\
\hline
\end{tabular}

$(-)$ : Absence $(+)$ : Present $(++)$ : Present and moderate $(+++)$ : Present and intense

Table 3 Most common diagnosis aspects of visceral leishmaniasis during pregnancy

\begin{tabular}{lll}
\hline & \multicolumn{2}{c}{ Diagnosis aspects of kala-azar } \\
\hline Epidemiological & Clinical & Laboratorial \\
\hline Origin of patient & Fever & \\
Vector previous contact & Adynamia & Pancytopenia \\
Endemic areas & Weight loss & Anemia \\
Presence of sick dogs & Hemorrhage & Leukopenia \\
Report of VL contact & Hepatosplenomegaly & Lymphocytosis \\
& Anemia & Thrombocytopenia \\
& Decline of general condition & Inversion albumin/globulin ratio \\
& & Immunoflourescence $>$ I: 40 \\
& & ELISA IgG/lgM positive \\
& & Bone marrow, Lymph nodes and Spleen biopsy \\
& & (parasite direct observation)
\end{tabular}

\section{DIAGNOSIS OF VISCERAL LEISHMANIASIS DURING PREGNANCY}

The diagnosis of VL follows successive steps that are based on epidemiological, clinical and laboratory data. These aspects are presented on Table 3.

\section{Epidemiological aspects}

The origin of the patient and their visits to endemic areas are extremely important for the establishment of the diagnosis of VL. Patients with characteristic symptoms who originate from endemic areas and report previous contact with individuals with the disease or the presence of sick dogs in the vicinity, in addition to information about the vector (trying to find out if the patient has been in contact with sandfly by its external and specific characteristics questioning), should be screened for possible VL infection ${ }^{1-3,7}$.

\section{Clinical aspects}

The clinical forms observed during pregnancy range from the inapparent form to the classical form of the disease. In most cases, fever is the first symptom, accompanied by adynamia, weight loss and hemorrhage, with the last symptom often being confused with hemorrhagic conditions related to pregnancy itself. The observation of hepatosplenomegaly can be impaired because of the growth of the uterus. Since the symptoms are nonspecific and are easily confused with other clinical entities, analysis of epidemiological and laboratory data is essential. The clinical diagnosis becomes easier as classical signs and symptoms of VL become more exuberant, including manifestations such as marked hepatosplenomegaly, significant weight loss, adynamia, intense anemia accompanied by an important decline in general 
condition, and hemorrhage. No reports exist regarding the presence of the refractory form of the disease during pregnancy ${ }^{9,27-30}$. In these situations, epidemiological and laboratory data should be analyzed as a whole to confirm the diagnosis of infection.

\section{Laboratory aspects}

The laboratory diagnosis of VL is based on nonspecific and specific subsidiary exams. Nonspecific subsidiary exams are important since they provide guidance regarding both the diagnostic suspicion and the patient's process of cure, based on alterations in blood cells and in protein metabolism. Blood counts generally identify pancytopenia, anemia, leukopenia, relative lymphocytosis and thrombocytopenia. The absence of eosinophils is a typical finding, but when associated with other diseases such as schistosomiasis or strongyloidiasis, the number of eosinophils might be normal or elevated. Protein determination shows a strong inversion of the albumin/globulin ratio, with patterns as marked as those observed in multiple myeloma ${ }^{1-3,7}$.

Specific subsidiary exams include serological and parasitological tests. Indirect immunofluorescence (IF) permits the determination of IgG and IgM class antibodies, with the result being considered positive at dilutions equal to or higher than 1: 40. Immunoenzymatic assays (ELISA) are increasingly used and permit the determination of IgG and IgM antibodies with sensitivity and specificity rates that are higher than $97 \%{ }^{1}$. Parasitological examination is performed on material preferentially obtained from bone marrow, lymph nodes or spleen. Spleen biopsies should be obtained in the hospital under surgical conditions. In pregnant patients, sternal bone marrow biopsies are preferred over lymph node aspirates and spleen biopsy.

\section{Differential diagnosis}

Many clinical entities can be confused with VL, among them a prolonged enterobacterial infection (a combination of schistosomiasis with salmonella or another enterobacteria) whose clinical manifestations perfectly overlap with the signs and symptoms of VL, malaria, brucellosis, typhoid fever, acute Chagas' disease, hepatosplenic schistosomiasis, lymphoma, multiple myeloma, sickle cell anemia, and leukemias ${ }^{1-3,7}$.

\section{TREATMENT}

VL requires hospitalization, which should be maintained throughout treatment. Pentavalent antimonial compounds $\left(\mathrm{Sb}^{+5}\right)$ are considered to be the drugs of choice in these cases. In an attempt to standardize the therapeutic scheme, the World Health Organization recommends that the antimonial dose be calculated in $\mathrm{mg} \mathrm{Sb}{ }^{+5} / \mathrm{kg} /$ day. The product marketed in Brazil is $\mathrm{N}$ methylglucamine antimoniate (Glucantime ${ }^{\circledR}$ ), which is available in the form of $5 \mathrm{ml}$ flasks containing $425 \mathrm{mg} / \mathrm{Sb}^{+5}$, corresponding to $85 \mathrm{mg} \mathrm{Sb}{ }^{+5} / \mathrm{ml}$. The recommended dose is $20 \mathrm{mg} \mathrm{Sb}{ }^{+5} / \mathrm{kg} /$ day, administered by the parenteral route (intravenous or intramuscular), with a maximum of three ampullae/day (1275 mg $\mathrm{Sb}^{+5} /$ day) for a minimum of 20 and a maximum of 40 consecutive days ${ }^{1,2,31}$.

Antimony is contraindicated in patients with renal or hepatic failure, cardiac arrhythmias and Chagas' disease. Clinical follow-up includes complementary exams (blood count, determination of urea, creatinine, glutamic-oxaloacetic transaminase (GOT), and glutamic-pyruvic transaminase (GPT)) which are recommended in order to detect possible time-dependent manifestations of intoxication. The most common side effects are arthralgia, myalgia, pruritus, adynamia, anorexia, nausea, vomiting, gastric fullness, heartburn, abdominal pain, fever, weakness, headache, dizziness, palpitation, insomnia, irritability, pyrogenic shock, and edema. Herpes zoster, acute renal failure and pancreatitis are severe complications observed with the use of antimonial drugs.

The most feared adverse effect of pentavalent antimonial drugs is cardiotoxicity, which should be monitored on periodic electrocardiograms (ECG) for the detection of changes in the QT segment. Nonspecific alterations in ventricular repolarization are frequent and, as long as the QT interval is not prolonged, medication should not be discontinued. The first control ECG should be obtained 5 days after the beginning of 
treatment. Discontinuation of treatment is indicated in cases of cardiotoxicity, renal failure and pancreatitis ${ }^{1,5,6,31}$.

In cases where leishmania is resistant to antimony, the second choice drug is amphotericin B. The total daily dose ranges from 1 to $1.5 \mathrm{mg} /$ $\mathrm{kg}$ (maximum of $50 \mathrm{mg} /$ day); however, treatment should be started with $0.5 \mathrm{mg} / \mathrm{kg} /$ day until the total daily dose of 1 to $1.5 \mathrm{mg} / \mathrm{kg}$ is reached. Each milligram of drug is reconstituted in $10 \mathrm{mg}$ distilled water and $1 \mathrm{mg}$ of the solution is diluted in $10 \mathrm{ml} \mathrm{5 \%}$ glucose serum at the time of administration. Due to the risk of precipitation, amphotericin B must not be administered together with other drugs or solutions containing electrolytes, and the drug should be protected from light. Amphotericin B is infused intravenously at a slow rate (over a period of 4 to 6 hours, at a maximum of $50 \mathrm{mg} /$ dose/day) on consecutive days for a period of 14 days. In view of its toxicity, amphotericin B should be administered under medical supervision and the patients should be under hospitalization ${ }^{1,5,6,31}$.

In the case of patients that are refractory to treatment with amphotericin $\mathrm{B}$, pentamidine is indicated at the dose of $4 \mathrm{mg} / \mathrm{kg}$, three times a week for 5 to 25 weeks, depending on the response. The drug is administered by the parenteral route (intramuscular or intravenous) and might cause local pain, nausea, vomiting, abdominal pain, hypotension, hypoglycemia, and diabetes mellitus ${ }^{31}$.

The treatment success rates are high, ranging from 95-100\% depending on the drug used. Drug resistance, when it occurs, is due to the patient's immunity factors, and has no relation to parasite factors at all ${ }^{1,9}$.

\section{TREATMENT OF PREGNANT WOMEN}

The occurrence of VL during pregnancy is rare, both in Brazil and worldwide, considering that $90 \%$ of cases of the disease are observed in children younger than 10 years of age. However, with the spreading of the disease to peri-urban areas, where adults have not generally been previously exposed to $L$. chagasi, cases of VL in pregnant women have been reported ${ }^{1,2,9}$. Congenital and post-natal transmission of leishmaniasis has already been documented. Therefore, treatment of pregnant women has a double indication: to treat the patient and to prevent vertical transmission $^{27-30,32}$.

Important considerations in this respect refer to the drugs currently available for the treatment of $\mathrm{VL}$ in pregnant women, their possible teratogenic effects and toxicity to the fetus. Despite the fact that pentavalent antimonial organic compounds have been used in clinical practice for more than 50 years, information on their safety during pregnancy is still scant. Some authors indicate that it should be avoided once teratogenity and security of these compounds during pregnancy are not well established ${ }^{33,34}$, whereas others say that mutagenic, carcinogenic and teratogenic risks of antimony compounds are not very important, and so the usage during pregnancy may not cause important maternal-fetal injury ${ }^{35}$.

Paumgartten and Chahoud ${ }^{34}$ described that the experimental repeated administration of meglumine antimoniate was embryolethal and teratogenic in rats, but no maternal toxicity and no reduction of fetal weight were noted in the treated groups. It was also reported that pentavalent antimony compounds cross the placental barrier and may impregnate fetal nervous tissue, leading to severe syndromes of mental retardation $^{36}$

Another clinical report has shown no adverse fetal effects of pentavalent antimony administered during the second trimester of gestation at the dose of $850 \mathrm{mg} \mathrm{Sb}^{+5} /$ day, with the child delivered at term showing no alterations and being free of the disease ${ }^{29}$. However, this report is the only one available thus far using antimony compounds during pregnancy, and cases of pregnant women being treated with antileishmanial drugs are rare (Table 4).

Amphotericin B is the second drug of choice for the treatment of VL in non-pregnant patients; however, due to its high nephro- and cardiotoxicity the drug should be administered under strict care. Since amphotericin B has been recognized as a drug with a leishmanicidal action but high toxic potential, therapeutic schemes have been modified over the years, a fact that led to progressive reduction and control of its toxicity and side effects $^{37,38,39}$. Amphotericin B crosses the pla- 
Table 4 Reports available in the literature regarding treatment of symptomatic pregnant women with visceral leishmaniasis $(\mathrm{VL})$

\begin{tabular}{lcccccc}
\hline No. of cases & Reference & Country & Drug used & Daily dose & Period & Congenital VL \\
\hline 5 & ${\text { Thakur et al. }{ }^{27}}^{28}$ & India & Amphotericin B & $1-20 \mathrm{mg} / \mathrm{kg}$ & $2^{\text {nd }}-3^{\text {rd }}$ trimester & No \\
I & Grandoni et al. $^{28}$ & Italy & Amphotericin B & $18 \mathrm{mg} / \mathrm{kg}$ & $3^{\text {rd }}$ trimester & No \\
I & Utili et al. ${ }^{29}$ & Italy & Antimony & $850 \mathrm{mg} \mathrm{Sb}+5$ & $2^{\text {nd }}$ trimester & No \\
I & Kumar et al. ${ }^{30}$ & India & Amphotericin B & $1 \mathrm{mg} / \mathrm{kg}$ & $3^{\text {rd }}$ trimester & No \\
I & Caldas et al. $^{9}$ & Brazil & Amphotericin B & $I \mathrm{mg} / \mathrm{kg}$ & I $^{\text {st }}$ trimester & No \\
\hline
\end{tabular}

cental barrier but plasma concentrations in the fetus do not exceed one third of those observed in maternal plasma ${ }^{31}$. Based on the high cure rates of kala-azar $(95-100 \%)^{1,9,39}$, the use of amphoterecin B has been extended and its safe use in pregnant women without repercussions on the fetus has been reported ${ }^{9,27,28,30}$ (Table 4).

Various other drugs have been employed in the treatment of VL, with aminosidine being another option for treatment during pregnancy. The precautions and restrictions are the same that apply to the use of aminoglycosides during pregnancy. The recommended daily dose is $12-16 \mathrm{mg} / \mathrm{kg}$, administered intramuscularly for 15-20 days. Another series lasting 10-15 days might be repeated one month after treatment if amastigote forms persist in the bone marrow. The response to aminosidine is generally slower than that observed during treatment with the first and second choice drugs previously mentioned. The monitoring of renal function is obligatory. However, no reports exist regarding the use of aminosidine during pregnancy ${ }^{1,9,27-30}$.

During the lactation period, if the mother is being treated with $\mathrm{Sb}^{+5}$ compounds, the newborn should be breast-fed 5 to 6 hours after drug administration to the mother, when antimony levels in the milk become neglible. If amphotericin B is being used, no remarkable recommendations concerning lactation are needed $^{31}$.

\section{CONCLUSIONS}

A present review of the literature shows that the occurrence of VL during pregnancy involves a real risk of vertical transmission ${ }^{4,18-26}$ as can be seen in Table 1. The reported cases of congenital leishmaniasis mainly involved untreated symptomatic women. Cure of newborns submitted to post-natal treatment was observed in $73 \%$ of cases $^{4,18-23,26}$ while death occurred in $27 \%$ of cases $^{24,25}$.

No vertical transmission was observed in the nine cases reported in the literature who received anti-leishmanial drugs during pregnancy ${ }^{9,27-30}$. This is evidence that the prenatal treatment of pregnant infected women results in no-newborn infection, but additional trials are needed to state whether treatment actually avoids the parasite infection to the fetus and how effective it really is during pregnancy (Table 4).

In the cases reported in Table 4, the drugs were administered after the second trimester at variable doses and the fact that these cases represented isolated reports using different and uncontrolled strategies did not permit a definition of the best therapeutic option ${ }^{9,27-30}$. Only one group studied a series of five patients using the same amphotericin $\mathrm{B}$ regimen administered to pregnant women and observed no mother-to-child transmission of the parasite ${ }^{27}$.

Caldas et al. ${ }^{9}$ reported on a 17-year-old Brazilian pregnant patient admitted with VL during the first trimester of gestation. This patient was treated with $1 \mathrm{mg} / \mathrm{kg}$ of amphotericin B for 14 days. The patient was then followed-up after treatment at 3-month intervals for 12 months, and demonstrating no signs or symptoms of VL. She had a vaginal delivery at 9 months gestation and gave birth to a healthy boy weighing $2485 \mathrm{~g}$, with no abnormalities upon physical examination. No vertical transmission was observed, and the child was followed-up clinically and serologically for 10 months without showing any signs or symptoms of the disease, even though he was living in an 
endemic area. Anatomopathological analysis of the placenta did not reveal any parasites, thus suggesting the absence of Leishmania transmission from the mother to the infant.

Until new studies become available, amphotericin $\mathrm{B}$ seems to be the first choice regimen while treating pregnant patients with kalaazar $^{9,27,28,30}$, leading to high cure rates associated with a reduced total dose, according to information extracted from the cases listed on Table 4.

Based on the above considerations, it is clear that more consistent studies are necessary to define the best and safest drug for women infected with $L$. chagasi during pregnancy, in order to prevent vertical transmission. During pregnancy, a shift from cell-mediated to humoral immunity has been described in mice as well as in humans ${ }^{40}$. Therefore, females may have a higher susceptibility to leishmaniasis during pregnancy, as has been shown in mice ${ }^{41}$. This may also suggest that pregnancy can trigger the (re)activaction of leishmaniasis ${ }^{4}$. According to Kumar et al. ${ }^{30}$ and Caldas et al. ${ }^{9}$, the institution of treatment is imperative in cases of pregnant women with leishmaniasis, with amphotericin B being recommended as the first choice drug because of its fewer maternal-fetal adverse effects.

\section{REFERENCES}

1. Alencar JE, Neves J, Dietze R. Leishmaniose visceral (calazar). In Veronesi R, Focaccia R, Dietze R, eds. Tratado de Infectologia, 9th edn. São Paulo: Atheneu, 1997

2. BRASIL. Fundação Nacional de Saúde. Guia de Vigilância Epidemiológic, 5th edn. Brasília, 2002

3. BRASIL. Fundação Nacional de Saúde. Doenças Infecciosas e Parasitárias. Guia de Bolso, 1st edn. Brasília, 1999

4. Meinecke CK, Schottelius J, Oskam L, et al. Congenital transmission of visceral leishmaniasis (kala azar) from an asymptomatic mother to her child. Pediatrics 1999;104:e65

5. Manson-Bahr PEC. Leishmaniasis. In: Hoeprich $\mathrm{PD}$, Jordan $\mathrm{MC}$, Ronald $\mathrm{AR}$, eds. Infectious Diseases. A Treatise of Infectious Processes, 5th edn. Philadelphia: J.B. Lippincott Company, 1994

6. Pearson RD, Sousa AQ. Leishmania species: visceral (kala-azar), cutaneous and mucosal leishmaniasis. In: Mandell GL, Bennett JE, Dolin R, eds. Principles and Practice of Infectious Diseases, 5th edn. London: Churchill Livingstone, 2000

7. Fundação Nacional de Saúde (FNS). Controle, diagnóstico e tratamento de Leishmaniose Visceral (Calazar). Brasília: Ministério da Saúde, Brasil, 1996

8. Vieira JBF, Coelho GE. Leishmaniose visceral ou calazar: aspectos epidemiológicos e de controle. Rev Soc Bras Med Trop 1998;31(SupplI):85-92

9. Caldas AJM, Costa JML, Gama MEA et al. Visceral leishmaniasis in pregnancy: a case report. Acta Tropica 2003;88:39-43
10. Nuwayri-Salti N, Khansa HF. Direct non-insectvector transmission of Leishmania parasites in mice. Int J Parasitol 1985;15:497 - 500

11. Gimbo A, Scirpo A, Ferro D, et al. Leishmania sp. in the submucosa of maternal post-abortive placenta in bitch. Parasitologia 1996;38:313

12. Andrade HM, Toledo VPCP, Marques MJ, et al. Leishmania (Leishmania) chagasi is not vertically transmitted in dogs. Vet Parasitol 2002;103:71-81

13. Krakowka S. Transplacentally acquired microbial and parasitic diseases of dogs. J Am Vet Med Assoc 1977;171:750-3

14. Harvey JW, Taboada J, Lewis JC. Babesiosis in a litter of pups. J Am Vet Med Assoc 1986; 192:1751-2

15. Dubey JP, Koestner A, Piper RC. Repeated transplacental transmission of Neospora caninum in dogs. J Am Vet Med Assoc 1990;197:857-60

16. Barber JS, Trees AJ. Naturally occurring vertical transmission of Neospora caninum in dogs. Int $J$ Parasitol 1998;28:57-64

17. Gtler RE, Lauricella MA, Solarz ND, et al. Dynamics of transmission of Trypanosoma cruzi in a rural area of Argentina. Rev Inst Med Trop São Paulo 1986;28:28-35

18. Low GC, Cooke WE. A congenital infection of kala azar. Lancet 1926;ii:1209-11

19. Banerji D. Possible congenital infection of kalaazar. J Indian Med Assoc 1955;24:433-5

20. Blanc C, Robert A. Cinquième observation de kala-azar congénital. La Presse Médicale 1984; 13:1751 
21. Mittal V, Sehgal S, Yadav TP, et al. Congenital transmission of Kala-azar. J Commun Dis 1987; 19:184-5

22. Nyakundi PM, Muigai R, Were JBO, et al. Congenital visceral leishmaniasis: case report. Trans R Soc Trop Med Hyg 1988;82:564

23. Yadav TP, Gupta H, Satteya U, et al. Congenital kala-azar. Ann Trop Med Parasitol 1989;83:535-7

24. Eltoum IA, Zijlstra EE, Ali MS, et al. Congenital kala-azar and leishmaniasis in the placenta. Am J Trop Med Hyg 1992;6:57-62

25. Elamin A, Omer MIA. Visceral leishmaniasis in a 6-week-old infant: possible congenital transmission. Trop Doct 1992;22:133-5

26. Sharma R, Bahl L, Goel A, et al. Congenital kalaazar: a case report. J Commun Dis 1996;28:59-61

27. Thakur CP, Sinha GP, Sharma V, et al. The treatment of leishmaniasis during pregnancy. Natl Med J India 1993;6:263-5

28. Grandoni L, Gaeta GB, Pellizzer G, et al. Mediterranean visceral leishmaniasis in pregnancy. Scand J Infect Dis 1994;26:627-9

29. Utili R, Rambaldi A, Tripodi MF, et al. Visceral leishmaniasis during pregnancy treated with meglumine antimonate. Infection 1995;23:182-3

30. Kumar A, Mittal M, Prasad S. Treatment of leishmaniasis in pregnancy. Int $J$ Gynaecol Obstet 2001;72:189-90

31. Mattos MS. Calazar. In: Schechter M, Marangoni DV, eds. Doenças Infecciosas: Conduta Diagnóstica e Terapêutica, 2nd edn. Rio de Janeiro: Guanabara Koogan, 1998

32. De Raadt P. Congenital trypanosomiasis and leishmaniasis. Arch Fr Pediatr 1985;42(Suppl 2): $925-7$

Received 08/01/03; ACCEPTED 12/02/03
33. Winship KA. Toxicity of antimony and its compounds. Adverse Drug Acute Poisoning Rev 1987;6:67-90

34. Paumgartten FJ, Chahoud I. Embryotoxicity of meglumine antimoniate in the rat. Reprod Toxicol 2001; 15:327-31

35. Leonard A, Gerber GB. Mutagenicity, carcinogenicity and teratogenicity of antimony compounds. Mutat Res 1996;366:1-8

36. Marsden PD. Old drugs for new diseases. Rev Soc Bras Med Trop 1985; 18:187-98

37. Mish M, Biswas UK, Jha DN, Khan AB. Amphotericin B for second-line treatment of Indian kala-azar. Lancet 1990;337:926

38. Giri OP. Amphotericin B therapy in kala-azar. $J$ Assoc Phys India 1993;4:91-93

39. Thakur CP, Singh SM, Hassan RK et al. Amphotericin B deoxycholate treatment of visceral leishmaniasis with newer modes of administration and precautions: a study of 938 cases. Trans R Soc Trop Med Hyg 1999;93:319328

40. Wegmann TG, Lin H, Guilbert LJ, et al. Bidirectional cytokine interections in the maternal-fetal relationship: is successful pregnancy a TH2 phenomenon? Immunol Today 1993; $14: 353-6$

41. Krishnan L, Guilbert LJ, Russel AS, et al. Pregnancy impairs resistance of C57BL/6 mice to Leishmania major infection and causes decreased antigen-specific IFN-gama responses and increased production of $\mathrm{T}$ helper 2 cytokines. $J$ Immunol 1996;156:644-52 


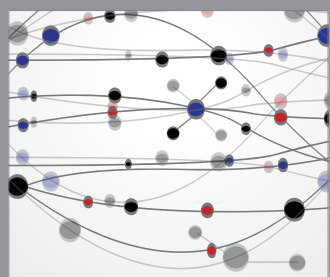

The Scientific World Journal
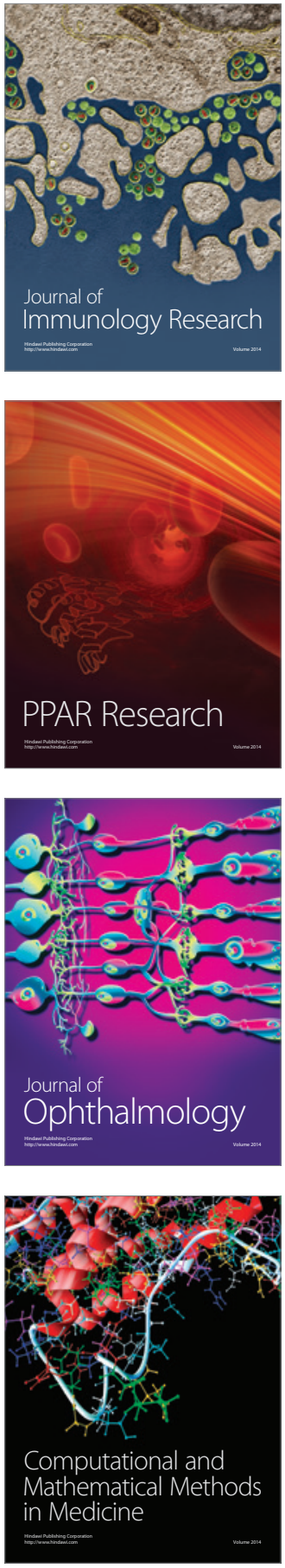

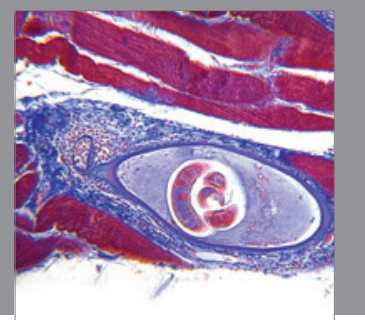

Gastroenterology

Research and Practice
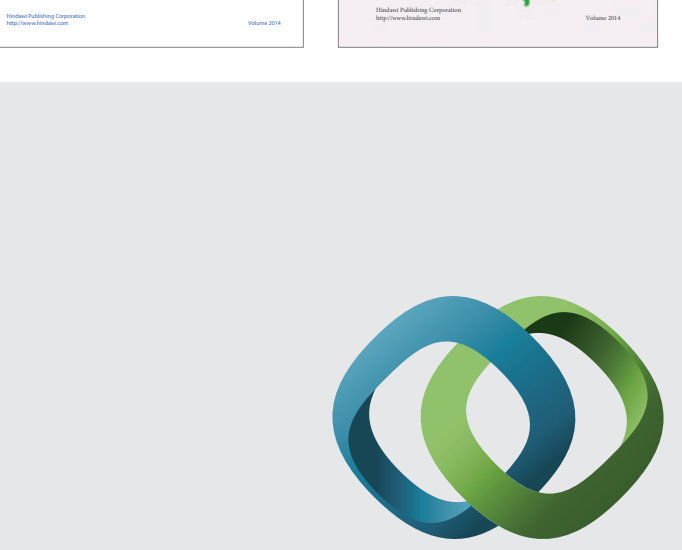

\section{Hindawi}

Submit your manuscripts at

http://www.hindawi.com
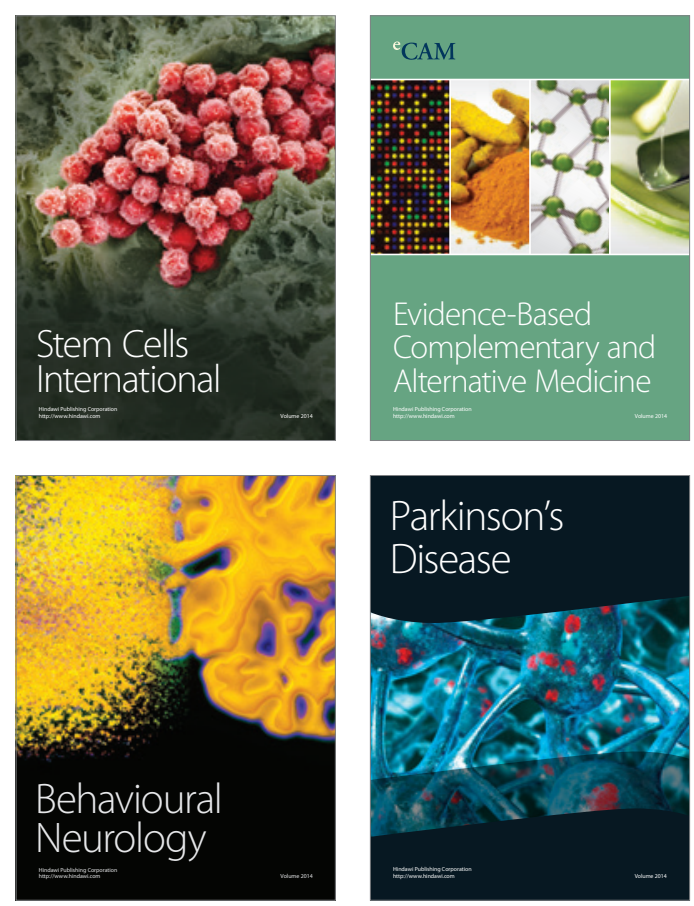

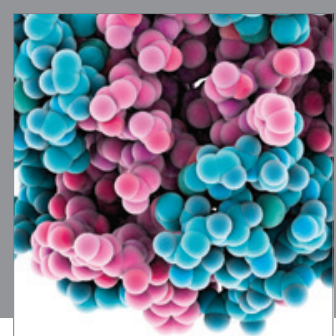

Journal of
Diabetes Research

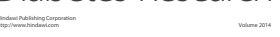

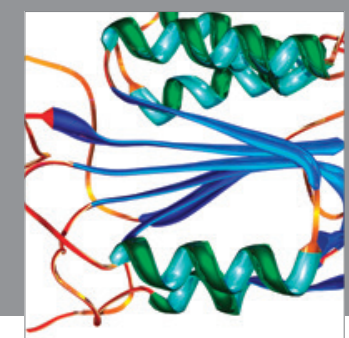

Disease Markers
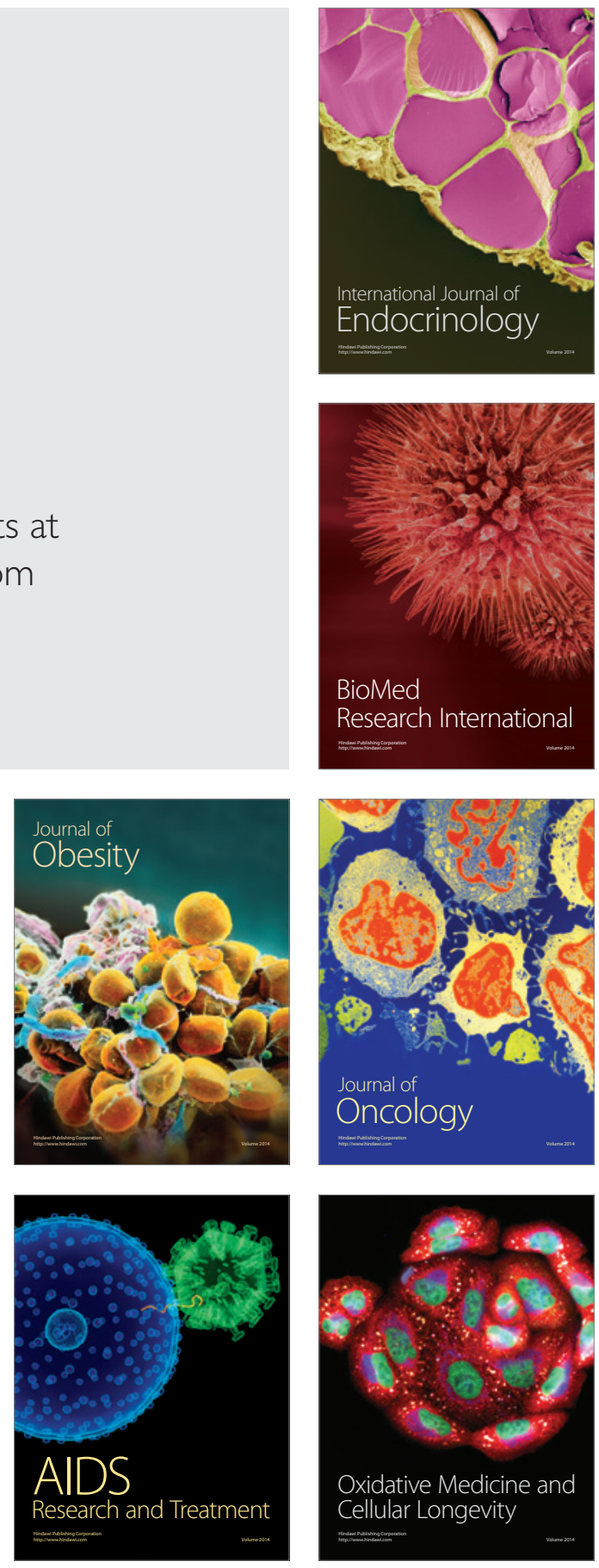